\title{
HYBRID KITOSAN/BENTONIT SEBAGAI MATRIKS UNTUK PELEPASAN ION AMONIUM DALAM AIR
}

\author{
Bambang Piluharto $^{1 *}$, Yusril Ihza Mahendra ${ }^{1}$, Novita Andarini ${ }^{1}$ \\ ${ }^{1}$ Jurusan Kimia, FMIPA \\ Universitas Jember \\ *email: bampito.fmipa@unej.ac.id
}

\begin{abstract}
Abstrak
Hybrid kitosan/bentonit dalam bentuk bead telah berhasil dibuat dengan berbagai rasio komposisi kitosan dan bentonit. Dalam penelitian ini, bead dari hybrid ini digunakan sebagai matriks untuk ion amonium. Bead dibuat dengan pengendapan suspensi kitosan dan bentonit menggunakan koagulan $\mathrm{NaOH}$. Bead hybrid yang diperoleh dikarakterisasi daya serap air (DSA) dan pelepasan ion amonium dalam air. Hasil yang diperoleh menunjukkan bahwa bentuk bead dipengaruhi oleh kandungan bentonit dalam hybrid. Peningkatan kandungan bentonit dalam hybrid menurunkan nilai DSA, namun meningkatkan pelepasan ion amonium dalam air. Sisa basa pada permukaan bead hybrid mempengaruhi deteksi pelepasan ion amonium dalam air.
\end{abstract}

Kata kunci: hybrid, bead, suspensi, daya serap air, pelepasan ion

\begin{abstract}
Chitosan/bentonite hybrid in the form of beads was successfully prepared in various of chitosan and bentonite composition ratio. In this study, beads of hybrid play role as matrix for ammonium ions. Beads prepared by precipitation of chitosan and bentonite suspension using $\mathrm{NaOH}$ as coagulant. Characterization beads obtained were carried out on water uptake and release of ammonia ions in the water. The results showed that forms of bead were affected by bentonite content in the hybrid. Increasing of bentonite content decreased water uptake of hybrid, however the release of ammonia ions in the water increased. Remaining base in the beads surface affected detection of release of ammonia ions in the water.
\end{abstract}

Keywords: hybrid, beads, suspension, water uptake, release of ions

\section{Pendahuluan}

Hasil beberapa kajian menunjukkan bahwa penggunaan pupuk secara konvensional pada tanaman hanya sekitar $25-50 \%$ yang dapat diserap tanaman, selebihnya dilepas ke lingkungan bersama air. Selain kurang efisien, kelebihan pupuk menimbulkan pencemaran lingkungan khususnya pencemaran tanah (Lubkowski et al., 2015). Sistem pelepasan pupuk secara terkendali (control released fertilizer, $C R F$ ) digunakan untuk mengurangi kelemahan-kelemahan penggunaan pupuk secara konvensional. Sistem ini terdiri dari suatu matriks padatan dan pupuk/nutrient. Pada prinsipnya, pelepasan pupuk dapat dikontrol melalui suatu matriks yang berfungsi sebagai penghalang selektif (selective barrier) (Azeem et al., 2014 dan Lu et al., 2015).

Sebagian besar material matriks dalam CRF dibuat dari polimer. Dari polimerpolimer tersebut, matriks yang digunakan dalam CRF adalah material yang berbasiskan polimer sintetik. Penggunaan polimer sintetik sebagai material sintetik 
didasarkan pada beberapa alasan, seperti proses pembuatannya mudah serta memiliki kestabilan kimia dan mekanik yang tinggi. Namun demikian, secara umum polimer sintetik memiliki kelemahan yakni kurang ramah lingkungan karena sulit terdegradasi (Lu et al., 2015).

Pengembangan matriks CRF berbasis bahan-bahan dapat terbiodegradasi telah banyak dilakukan. Kitosan, pati, poliuretan, zeolite, bentonit dan bahan-bahan berbasis biomassa adalah material-material yang bersifat ramah lingkungan. Kitosan adalah salah satu material yang banyak digunakan sebagai matrik CRF didasarkan dari sifatsifatnya antara lain daya serap air yang tinggi, tidak beracun, dan dapat terbiodegradasi (Croisier dan Jerome, 2013). Namun demikian, kitosan memiliki kelemahan dari stabilitas mekanik yang rendah. Dengan demikian, pengembangan kitosan sebagai matriks untuk CRF perlu diarahkan untuk mengatasi kelemahan sifat mekaniknya.

Penelitian ini bertujuan membuat matriks berbasis kitosan untuk pelepasan ion ammonia dalam air. Dalam penelitian ini, matriks dibuat dari campuran kitosan dengan bentonit, yang selanjutnya disebut sebagai hybrid kitosan/bentonit. Beberapa kajian sebelumnya terkait dengan penambahan bentonit pada kitosan menunjukkan peningkatan kestabilan mekanik (Histrodor, 2009, Teofilovic et al., 2014).

\section{Metode Penelitian \\ Alat dan Bahan}

Peralatan yang digunakan adalah Ion selective electrode $\mathrm{NH}_{4}{ }^{+}$ELIT 8051 dengan reference electrode ELIT 003n (NICO 2000), pH meter (Hobrida), kamera digital, dan beberapa peralatan gelas. Adapun bahan yang adalah kitosan (berat molekul (BM) 310 - $375 \mathrm{kDa}$ ) dan Bentonit (BM $284 \mathrm{~g} / \mathrm{mol}$ ) diproleh dari Sigma Aldrich. Asam Asetat glasial, sodium klorida, ammonium klorida, perak nitrat dan tembaga sulfat pentahidrat diperoleh dari Merck. Akuades diperoleh dari distilasi air di laboratorium kimia analitik Universitas Jember.

\section{Prosedur penelitian}

Prosedur pembuatan hybrid kitosan bentonit mengikuti prosedur yang telah dibuat Histrodor et al. (2012), namun dilakukan modifikasi dengan menjadikan campuran suspensi (kitosan dan bentonit) dalam bentuk bead. Dalam penelitian ini, campuran suspensi dibuat dengan berbagai perbandingan komposisi berat antara kitosan dan bentonit, yaitu $1: 0 ; 1: 1 ; 2: 1$ dan 3:1.

Pembuatan bead dilakukan dengan memasukkan campuran suspensi ke dalam spuit (jarum suntik) ukuran $20 \mathrm{~mL}$, kemudian diteteskan pelan-pelan ke dalam beaker gelas $500 \mathrm{~mL}$ yang berisi larutan $\mathrm{NaOH} 2 \mathrm{M}$ disertai pengadukan. Bead yang diperoleh selanjutnya disaring dan diikuti pencucian dengan akuades beberapa kali sampai diperoleh $\mathrm{pH}$ yang netral. Bead selanjutnya dikeringkan di oven pada suhu $40{ }^{\circ} \mathrm{C}$ selama 24 jam.

Prosedur penentuan DSA mengikuti prosedur yang dilakukan Piluharto et al. (2011), dengan rumus sebagai berikut:

$$
D S A=\frac{W_{b}-W_{k}}{W_{k}} \times 100 \%
$$

Pelepasan ion ammonia dalam air menggunakan uji statis, sesuai dengan prosedur yang dilakukan oleh Tomasweska dan Jarosiewiz (2002). Pengukuran dilakukan selama 8 hari, dengan pengamatan pelepasan ion ammonia dilakukan setiap hari. Pelepasan ion ammonia diukur secara potensiometri menggunakan elektroda ion selektif (EIS) amonium.

\section{Hasil dan Pembahasan}

Bead Hybrid Kitosan/Bentonit

Matrik hybrid yang diperoleh dari berbagai rasio kitosan terhadap bentonit ditunjukkan pada Gambar 1. Secara fisik, bentuk bead kitosan dan hybridnya diamati secara makro dan mikro. Secara makro 
menggunakan kamera dengan resolusi 5.0 MPixel, sementara secara mikro menggunakan miroskop optic dengan perbesaran 30 kali. Berdasarkan gambar tersebut, tampak bahwa kitosan tanpa penambahan bentonit (1:0) membentuk bead yang berekor, sementara bead hybrid menghasilkan bentuk yang lebih bulat tanpa ekor. Dari warnanya, beads kitosan tanpa penambahan bentonit berwarna putih transparan, sementara bentuk hybrid berwarna coklat keabu-abuan. Bentuk fisik bead kitosan tanpa bentonit yang pipih terjadi saat bead dikeringkan. Dalam keadaan kering, air yang ada dalam kitosan akan berkurang, sehingga interaksi kitosan dengan air melalui ikatan hidrogen berkurang. Akibatnya, bead yang diperoleh berubah dari bentuk bulat menjadi pipih. Sementara bead pada hybrid kitosan/bentonit dalam bentuk kering memiliki bentuk bulat seperti pada keadaan basahnya, namun memiliki ukuran yang lebih kecil. Stabilnya bentuk bead hybrid kitosan/bentonit didasarkan pada interaksi kuat antara kitosan dengan bentonit yang menghasilkan suatu struktur yang berlapis, seperti ditunjukkan pada Gambar 2. (Histrodor, et al, 2012).

\begin{tabular}{|c|c|c|c|c|}
\hline \multirow{2}{*}{$\begin{array}{l}\text { Rasio } \\
\text { hybrid }\end{array}$} & \multicolumn{2}{|c|}{ Sifat Fisik } & \multicolumn{2}{|c|}{ Foto } \\
\hline & Warna & Bentuk & (skala makro) $^{\mathrm{a}}$ & (skala mikro) $^{b}$ \\
\hline $1: 0$ & Putih & Pipih & & \\
\hline $3: 1$ & $\mathrm{Abu}-\mathrm{abu}$ & Bulat & & \\
\hline $2: 1$ & $\mathrm{Abu}-\mathrm{abu}$ & Bulat & ${ }^{2} 6$ & \\
\hline $1: 1$ & $\mathrm{Abu}-\mathrm{abu}$ & Bulat & & \\
\hline
\end{tabular}

Gambar 1. Bentuk fisik bead kering dari hybrid kitosan/bentonit. ${ }^{\mathrm{a}}$ Gambar diperoleh menggunakan kamera dengan resolusi 5.0 MPixel. ${ }^{\mathrm{b}} \mathrm{Gambar}$ diperoleh menggunakan mikroskop optik dengan perbesaran $30 \times$. 


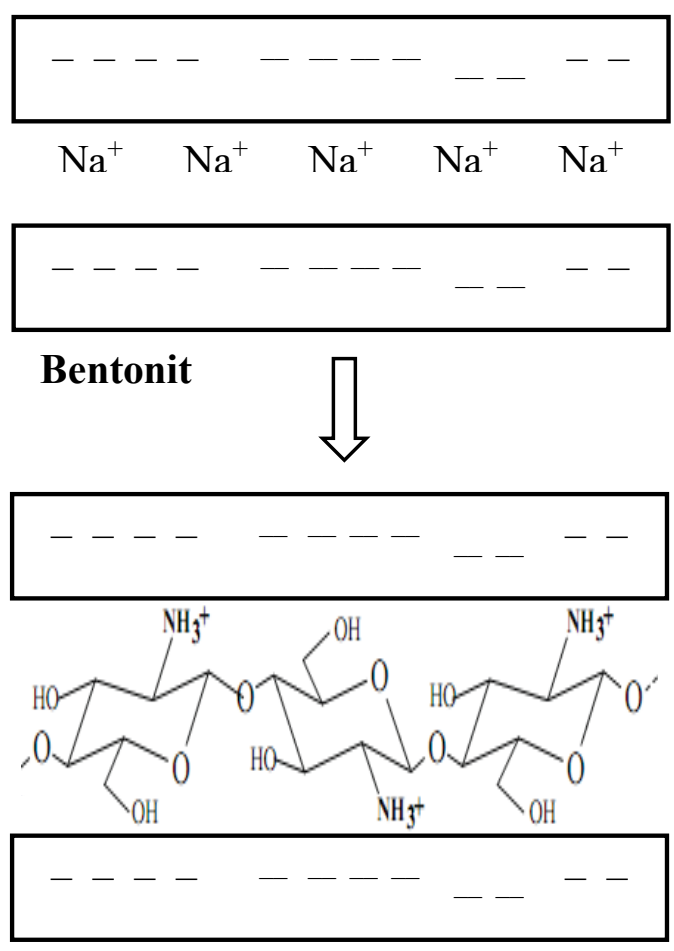

Kitosan/Bentonit

Gambar 2. Interaksi kitosan dengan bentonit (Histrodor et al., 2012)

Karakterisasi Sifat Beads sebagai Matriks untuk $C R F$

Daya serap air (DSA)

Gambar 3 menunjukkan hubungan DSA dengan berbagai komposisi hybrid kitsan bentonit. Tampak bahwa semakin tinggi kandungan bentonit dalam komposisi hybrid, DSA hybrid semakin menurun. Penurunan DSA ini dapat dijelaskan dari interaksi kitosan dengan air dan kitosan dengan bentonit. Pada hybrid dengan rasio 1:0, dimana tidak ada penambahan bentonit didalamnya. Ketika kitosan direndam di dalam air, terjadi absorpsi air oleh kitosan. Absorpsi ini berkaitan dengan interaksi gugus-gugus hidrofilik dari kitosan $(-\mathrm{OH}$ dan $-\mathrm{NH}_{2}$ ) dengan molekul air. Banyaknya gugus hidrofilik pada kitosan berperan besar terhadap daya serap yang besar terhadap air.

\section{Pelepasan ion amonium dalam air}

Karakterisasi pelepasan ion amonium dilakukan dalam air. Uji pelepasan ion amonium dilakukan selama 7 hari. Hasil yang diperoleh ditunjukkan pada Gambar 4. Tampak dalam gambar tersebut, pelepasan ion $\mathrm{NH}_{4}{ }^{+}$dari matriks hybrid dengan berbagai rasio komposisi memiliki pola yang mirip. Pelepasan ion $\mathrm{NH}_{4}{ }^{+}$ menunjukkan peningkatan sampai hari ke2, pada semua rasio komposisi hybrid, kecuali hybrid dengan rasio 1:1 yang meningkat sampai hari ke-3. Peningkatan hari berikutnya, konsentrasi ion $\mathrm{NH}_{4}{ }^{+}$terus menurun sampai hari ke-7. Dari berbagai rasio komposisi tersebut, rasio kitosan/bentonit 1:1 menunjukkan kecepatan pelepasan ion $\mathrm{NH}_{4}{ }^{+}$yang paling tinggi, diikuti dengan rasio $2: 1,3: 1$ dan 1 : 0 . Fenomena pelepasan ion $\mathrm{NH}_{4}{ }^{+}$yang dihasilkan dalam penelitian ini tidak seperti pada pelepasan dalam sistem controlledrelease pada umumnya, dimana dengan meningkatnya waktu, pelepasan bahan aktif (ion $\mathrm{NH}_{4}^{+}$) terus meningkat sampai diperoleh pelepasan yang konstan.

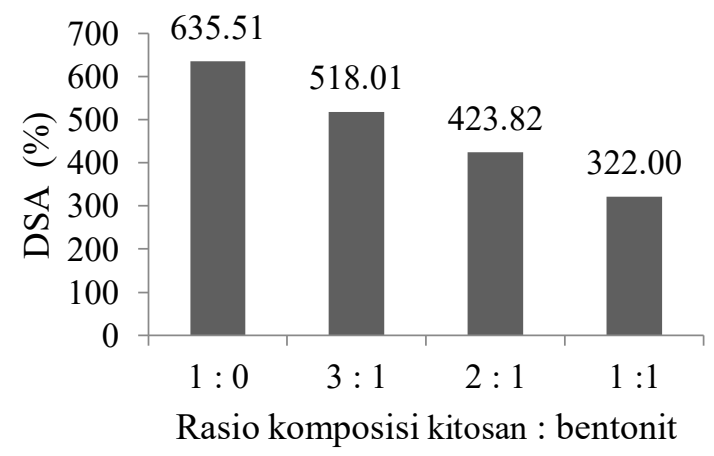

Gambar 3. Daya serap air (DSA) hybrid terhadap rasio komposisi kitosan/bentonit

Sementara hybrid dengan rasio lainnya, dimana ada penambahan bentonit di dalamnya, menunjukkan DSA yang lebih kecil disbanding DSA pada hybrid 1:0. Interaksi yang kuat dari gugus-gugus hidrofilik kitosan (-OH dan $-\mathrm{NH}_{2}$ ) dengan gugus-gugus pada bentonit berakibat pada berkurangnya absorpsi terhadap molekul air. Tampak bahwa pada hybrid dengan rasio 1:1 dimana bentonit memiliki kandungan paling tinggi menunjukkan DSA paling kecil. 


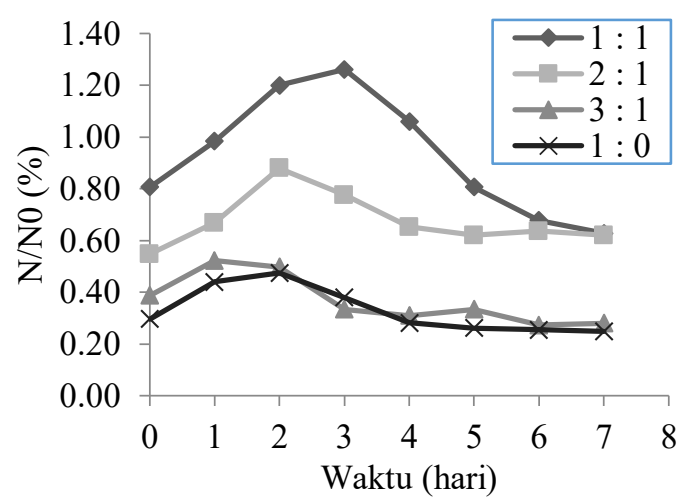

Gambar 4. Pelepasan ion $\mathrm{NH}_{4}{ }^{+}$dalam air terhadap waktu (hari)

Pada dasarnya, ion $\mathrm{NH}_{4}{ }^{+}$dalam air mengalami reaksi kesetimbangan seperti persamaan 2. Melihat reaksi di atas, ion $\mathrm{NH}_{4}{ }^{+}$berada dalam kesetimbangan dengan $\mathrm{NH}_{3}$. Keberadaan ion $\mathrm{NH}_{4}{ }^{+}$dipengaruhi oleh $\mathrm{pH}$ dalam sistem kesetimbangan tersebut dipengaruhi oleh $\mathrm{pH}$ (Orion, 2009). Dalam pH asam reaksi bergeser kea rah pembentukan ion $\mathrm{NH}_{4}^{+}$, sebaliknya pada kondisi basa reaksi bergeser kearah pembentukan $\mathrm{NH}_{3}$. Fakta yang terjadi dalam penelitian ini, larutan sampel keadaannya cenderung basa dengan bertambahnya waktu (Gambar 5). Kondisi larutan yang bersifat basa berakibat pada pergeseran kesetimbangan mengarah ke pembentukan $\mathrm{NH}_{3}$ (ke kanan).

$$
\mathrm{NH}_{4(a q)}^{+}+\mathrm{H}_{2} \mathrm{O}_{(l)} \rightleftharpoons \quad, \quad+\mathrm{H}_{3} \mathrm{O}_{(a q)}^{+}
$$

Kondisi larutan yang basa, dimungkinkan terjadi dari sisa $\mathrm{NaOH}$ yang ada pada permukaan bead. Seperti dinyatakan dalam bagian metodologi di atas, $\mathrm{NaOH}$ berperan dalam koagulasi bead hybrid. Pencucian yang tidak maksimal, menyebabkan masih ada sisa $\mathrm{NaOH}$ dalam permukaan bead. Karena $\mathrm{NaOH}$ adalah basa kuat maka akan terurai secara sempurna menjadi ion $\mathrm{OH}^{-}$. Keberadaan ion $\mathrm{OH}^{-}$dalam larutan, akan menggeser kesetimbangan ke arah pembentukan $\mathrm{NH}_{3}$. Akibat pergeseran ini, pelepasan ion $\mathrm{NH}_{4}{ }^{+}$ dari hybrid seharusnya mengalami peningkatan dengan meningkatnya waktu, menjadi berkurang karena berubah menjadi $\mathrm{NH}_{3}$

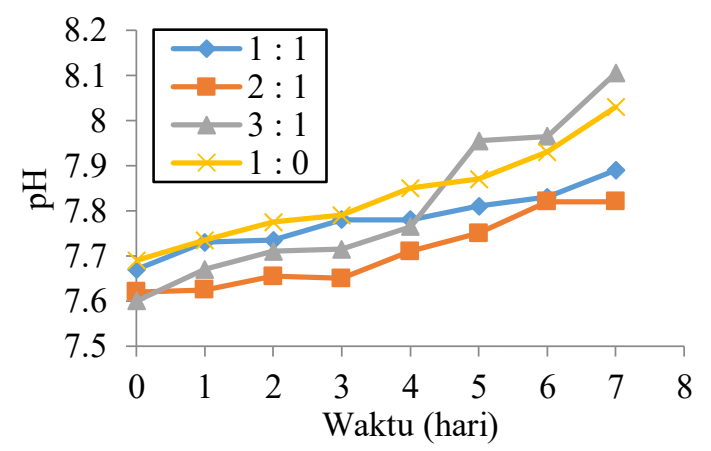

Gambar 5. Perubahan $\mathrm{pH}$ terhadap waktu (hari)

\section{Kesimpulan}

Berdasarkan analisis data yang diperoleh, diperoleh kesimpulan bahwa bead hybrid kitosan/bentonit dipengaruhi oleh jumlah kandungan bentonit dalam komposisi hybridnya. Daya serap air (DSA) hybrid mengalami penurunan sesuai bertambahnya kandungan bentonit, dengan urutan sebagai berikut $1: 0>3: 1>2: 1>$ 1 : 1. Ditinjau dari pelepasan ion $\mathrm{NH}_{4}{ }^{+}$ dalam air, hybrid dengan rasio kitosan/bentonit 1:1 memiliki kecepatan pelepasan ion $\mathrm{NH}_{4}{ }^{+}$yang paling tinggi, disusul hybrid dengan rasio 2:1, 3:1 dan 1: 0 . Kondisi keasaman (pH) larutan, berpengaruh pada deteksi ion $\mathrm{NH}_{4}{ }^{+}$dalam air.

\section{Daftar Pustaka}

Hristodor, Vrinceanu, Pui, Novac, Copcia, and Popovici (2012). Textural and Morphological Characterization of Chitosan/Bentonite Nanocomposite, Environmental Engineering and Management Journal, 11, 573 - 578.

Lu, P., Zhang Y., Jia, C., Wang, C., Li, X., and Zhang, M. (2015). Polyurethane from Liquefied Wheat Straw as Coating Material for Controlled Release Fertilizers, Bioresources, 10, $7877-7888$ 
Lubkowski K., Smorowska A., Grzmil B., and Kozlowska, A. (2015). Controlled release fertilizer prepared using a biodegradable aliphatic copolyester of poly (butylene succinate) and dimerized fatty acid, Journal of Agriculture and Food Chemistry, 63, $2597-2605$

Orion (2009). User Guide Standard Ammonia Ion Selective Electrode, Thermo Fisher Scientific Inc.,

Piluharto, B., Suendo, V., Ciptati T. and Radiman, C. L. (2011). Strong Correlation between Membrane Effective Fixed Charge and Proton Conductivity in The Sulfonated Polysulfone Cation-Exchange Membranes, Ionics, 17, 229 - 238.

Teofilovic, V. Pavlicevic, J. Bera, O. Jovicic, M. Simendic, J.B. Szecsenyi, K. M. and Arogus, A. (2013). Preparation and Thermal Properties of Chitosan/Bentonite Composite Beads, Hemijska Industrija, 68, 653 659

Tomaszewska, M. and Jarosiewicz, A. (2002). Use of Polysulfone in Controlled-Release NPK Fertilizer Formulations. Journal of Agriculture and Food Chemistry, 50, 4634 - 4639

Nakatani, N., Takamori, H., Takeda, K. and Sakugawa, H. (2009). Transesterification of soybean oil using combusted oyster shell waste as a catalyst. Bioresource Technology, 100, 1510 1513.

Ngamcharussrivichai, C., Nunthasanti, P., Tanachai, S. and Bunyakiat, $\mathrm{K}$. (2010). Biodiesel production through transesterification over natural calciums. Fuel Processing Technology, 91, 1409-1415. 